\title{
Pattern of premature degenerative changes of the cervical spine in patients with spasmodic torticollis and the impact on the outcome of selective peripheral denervation
}

\author{
S J Chawda, A Münchau, D Johnson, K Bhatia, N P Quinn, J Stevens, A J Lees, \\ $\mathrm{J}$ D Palmer
}

\begin{abstract}
Objectives-To characterise the pattern of and risk factors for degenerative changes of the cervical spine in patients with spasmodic torticollis and to assess whether these changes affect outcome after selective peripheral denervation.

Methods-Preoperative CT of the upper cervical spine of 34 patients with spasmodic torticollis referred for surgery were reviewed by two radiologists blinded to the clinical findings. Degenerative changes were assessed for each joint separately and rated as absent, minimal, moderate, or severe. Patients were clinically assessed before surgery and 3 months postoperatively by an independent examiner using standardised clinical rating scales. For comparison of means a $\boldsymbol{t}$ test was carried out. To determine whether an association exists between the side of degenerative changes and type of spasmodic torticollis a $\chi^{2}$ test was used. Changes in severity, disability, and pain before and after surgery were calculated using a Wilcoxon matched pairs signed ranks test.
\end{abstract}

Results-Fourteen out of 34 patients had moderate or severe degenerative changes. They were predominantly found at the $\mathrm{C} 2 / \mathrm{C} 3$ and $\mathrm{C} 3 / \mathrm{C} 4$ level and were significantly more likely to occur on the side of the main direction of the spasmodic torticollis $(p=0.015)$. There was no significant difference in age, sex, duration of torticollis, overall severity, degree of disability, or pain between the group with either no or minimal changes and the group with moderate or severe changes. However, in the second group the duration of inadequate treatment was longer (10.1 $v 4.8$ years; $p=0.009$ ), head mobility was more restricted $(p=0.015)$, and head tremor was more severe $(\mathrm{p}=\mathbf{0 . 0 1})$. At 3 months postoperatively, patients with no or minimal degenerative changes showed a significant improvement in pain and severity whereas no difference was found in those with moderate or severe changes.

Conclusions-Patients with spasmodic torticollis have an increased risk of developing premature degenerative changes of the upper cervical spine that tend to be on the side towards which the head is turned or tilted and compromise outcome after surgery. Effective early treatment of spas- modic torticollis with botulinum toxin seems to have a protective effect. Patients with spasmodic torticollis and restricted head mobility who do not adequately respond to treatment should undergo imaging of the upper cervical spine. Patients with imaging evidence of moderate or severe degenerative changes seem to respond poorly to selective peripheral denervation.

(F Neurol Neurosurg Psychiatry 2000;68:465-471)

Keywords: osteoarthritis; spasmodic torticollis; computed tomography; selective peripheral denervation

Idiopathic spasmodic torticollis is the most common form of adult onset focal dystonia. ${ }^{1}$ It is characterised by repetitive or sustained contractions of neck muscles that lead to an abnormal posture of the head and neck. ${ }^{2-4}$ Depending on the pattern of muscular activity the head is rotated, tilted, flexed, or extended but often there is a combination of these movements. ${ }^{5}$ Spasmodic torticollis often causes pain, interferes with daily activities, and can be very socially disabling. ${ }^{6-8}$ Secondary problems include dysphagia ${ }^{9}$ and impairment of balance. ${ }^{10}$

Non-physiological repetitive head and neck movements can stress the joints in the cervical spine. Cervical spondylosis with resulting radiculopathy or myelopathy has been reported in patients with generalised dystonia ${ }^{11-26}$ and, rarely, in patients with spasmodic torticollis. ${ }^{1126-28}$ It has also been noted that degenerative changes in patients with generalised dystonia tend to occur prematurely. ${ }^{11-26}$ So far no systematic study considering this problem using modern imaging methods has been carried out.

We investigated 34 patients with spasmodic torticollis who were referred for surgery (selective peripheral denervation (SPD) $)^{29-31}$ because of primary resistance to or secondary failure of botulinum toxin (BT) treatment. In all patients CT of the cervical spine from the occipitocervical junction down to the mid/upper cervical spine was carried out mainly to look for craniovertebral abnormalities that may not have been apparent on plain radiographs such as os odontoideum and rotatory atlantoaxial dislocation. ${ }^{32}$ Plain radiographs of the cervical spine were not always available to us; therefore degenerative changes were only assessed on 


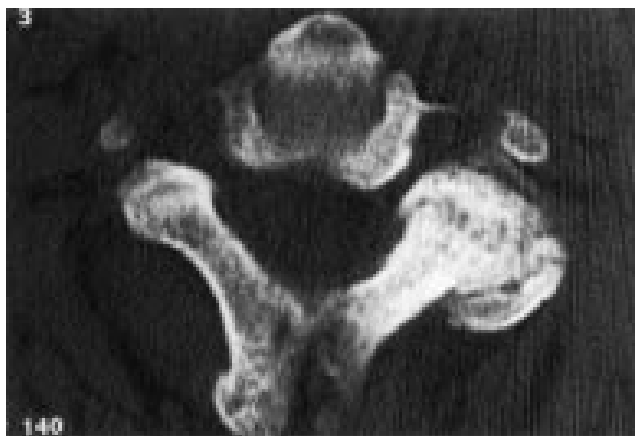

Patient with left tremulous torticollis with left grade 3 and right grade 0 changes at the $C 2 / 3$ facet joints.

CT. In some patients MRI of the cervical spine was also performed. All patients were assessed clinically before surgery and 3 months postoperatively by an independent examiner using standardised rating scales.

\section{Methods}

IMAGING STUDIES

Craniocervical CT was carried out in all 34 patients on a Siemens Somaton plus 4 (VB3 version OB). A single spiral scan (kVp 120, 200 $\mathrm{mA}$ ) continuing in a caudal direction was obtained ( $2 \mathrm{~mm}$ collimation, with a table feed of $5 \mathrm{~mm} / \mathrm{s}$ ) and the data reconstructed as $1 \mathrm{~mm}$ thick slices. Axial sections were obtained from the clivus to the midcervical spine with coronal and sagittal reformats. All images were retrospectively reviewed by two radiologists (SJC and DJ) and any differences in interpretation were resolved by consensus. The radiologists were blind to the clinical findings in these patients.

The joints considered were: occipital condyle-C1 lateral mass articulation (O-C1), $\mathrm{C} 1-\mathrm{C} 2$ lateral mass articulations, $\mathrm{C} 1$ anterior arch-C2 odontoid peg articulation, C2/3 facet and uncovertebral joint articulations, and also lower levels if they were scanned. The degree of spondylotic change was assessed from a combination of loss of joint space, subchondral sclerosis or cysts, and osteophytes. Degenerative changes were recorded on a scale of $0-3$ $(0=$ normal,$\quad 1=$ minimal, $2=$ moderate, and $3=$ severe). Apart from the C1 arch-C2 peg articulation, the left and right joints were scored individually. Figure 1 shows an example of grade 3 degenerative change.

Eighteen patients also had MRI of the cervical spine and these were reviewed with particular emphasis on the cervical spinal cord. All MRI images were performed on a GE Vectra $0.5 \mathrm{~T}$ scanner. A quadrature anterior neck coil was used. T1 sagittal spin echo (TR/TE,

Table 1 Spasmodic torticollis patient characteristics

\begin{tabular}{lrlllll}
\hline Type of $S T$ & $n$ & $\begin{array}{l}\text { Sex } \\
(M: F)\end{array}$ & $\begin{array}{l}\text { Median age } \\
(y \text { (range) })\end{array}$ & $\begin{array}{l}\text { Median duration } \\
(y \text { (range) }\end{array}$ & $\begin{array}{l}\text { Severity }^{*} \\
\text { (mean }(S D))\end{array}$ & $\begin{array}{l}\text { Primary } \\
\text { failure }\end{array}$ \\
\hline R Torticollis & 5 & $3: 2$ & $54(32-57)$ & $12(9-18)$ & $20.2(5)$ & \\
L Torticollis & 11 & $4: 7$ & $49(30-60)$ & $11(2-26)$ & $20(4.2)$ & 3 \\
R Laterocollis & 6 & $3: 3$ & $52(44-59)$ & $12(7-22)$ & $19.5(6)$ & \\
L Laterocollis & 6 & $1: 5$ & $50(38-66)$ & $16(4-21)$ & $22.3(1.6)$ & 1 \\
Anterocollis & 1 & $1: 0$ & 53 & 17 & 16 & 1 \\
Retrocollis & 5 & $4: 1$ & $56(23-59)$ & $10(3-37)$ & $21(4.1)$ & 1 \\
Total & 34 & $16: 18$ & $53.5(23-66)$ & $11.5(2-37)$ & $20.4(4)$ & 6 \\
\hline
\end{tabular}

^As determined by the TWSTRS. $\mathrm{R}=$ right, $\mathrm{L}=$ left.
440/15; FOV $24 \mathrm{~cm}$; $\mathrm{NEX}=4$; matrix $=256 \times 192)$ and $\mathrm{T} 2$ sagittal fast spin echo (TR/TE, 5000/130; FOV $24 \mathrm{~cm}$; NEX=4; matrix $=160 \times 256$ ) and relevant axial T2 gradient echo images (flip angle 20 degrees; TR/TE, 560/25; FOV 16 cm; NEX=5; matrix $=160 \times 224$ ) were obtained. The sagittal sequences were $4 \mathrm{~mm}$ thick with a $1 \mathrm{~mm}$ interslice gap.

\section{PATIENTS}

A total of 34 patients with spasmodic torticollis, all of whom had received BT injections in the past, were referred for consideration of SPD surgery over the period 1997-8. The interval between the last botulinum toxin (BT) injection and the investigation before surgery was at least 4 months in all patients and often more than 6 months. Patients were referred for surgery because of either primary or secondary failure of BT treatment. Patient characteristics are given in tables 1 and 4 . Of the 34 patients referred 22 underwent surgery. They were all examined again 3 months after surgery.

In addition to a detailed history from each patient, medical notes were studied to determine the documented response to $\mathrm{BT}$ injections over the years. Patients were classified as having predominantly torticollis (head rotation in the horizontal plane), laterocollis (head tilt in the coronal plane), or anterocollis or retrocollis (head flexion or extension). This was done taking into account the primary dystonic position and the degree of restriction of head movements. For instance, a patient with a combination of head rotation to the right and tilt to the left was labelled primarily right torticollis when left rotation was more restricted than right tilt and vice versa. Severity at the time of the investigation was determined using the Toronto western spasmodic torticollis rating (TWSTR) severity scale. ${ }^{33}$ This scale takes into account the dystonic position of the head, the effectiveness of any sensory trick, and how long the patient can keep the head in a straight position and estimates the degree of head mobility and position of the shoulder. The maximum severity on this scale is 35 .

To further characterise restriction of head and neck movements we used a geniometer to measure the degree of head mobility opposite to the direction of the dystonic head positionfor example, contralateral tilt in a patient with laterocollis. Firstly, patients were asked to actively tilt their head in the direction opposite to the main dystonic position; secondly, the head was moved passively. If the patient was able to actively or passively tilt the head less than 5 degrees past the midline a score of 6 was given. The rating was $5,4,3,2,1$, or 0 if the contralateral tilt was at best $10,15,20,25$, and 30 degrees or more than 30 degrees, respectively. For contralateral active or passive rotation the rating was as follows: $6=$ contralateral rotation of less than 10 degrees, $5=$ contralateral rotation possible up to 20 degrees, $4=$ up to 30 degrees, $3=$ up to 40 degrees, $2=$ up to 50 degrees, $1=$ up to 60 degrees, and $0=$ more than 60 degrees. To assess the overall restriction of 
Table 2 Radiological findings in 14 spasmodic torticollis patients with moderate to severe degenerative changes

\begin{tabular}{|c|c|c|c|c|c|c|c|c|c|c|c|c|c|c|c|c|c|}
\hline \multirow[b]{2}{*}{ Type of $S T$} & \multicolumn{2}{|c|}{$A O \mathcal{F T}$} & \multirow[t]{2}{*}{$\begin{array}{l}A A \mathcal{F} T \\
P E G\end{array}$} & \multicolumn{2}{|c|}{$\begin{array}{l}A A \mathfrak{F T} \\
L M\end{array}$} & \multicolumn{2}{|c|}{$\begin{array}{l}\text { C2/3 } \\
\text { FACETS }\end{array}$} & \multicolumn{2}{|c|}{$\begin{array}{l}\text { C2/3 U/C } \\
\mathfrak{f T S}\end{array}$} & \multicolumn{2}{|c|}{$\begin{array}{l}\text { C3/4 } \\
\text { FACETS }\end{array}$} & \multicolumn{2}{|c|}{$\begin{array}{l}\text { C3/4 U/C } \\
\text { FTS }\end{array}$} & \multicolumn{2}{|c|}{$\begin{array}{l}\text { C4/5 } \\
\text { FACETS }\end{array}$} & \multicolumn{2}{|c|}{$\begin{array}{l}\text { C4/5 U/C } \\
\text { fTS }\end{array}$} \\
\hline & $L$ & $R$ & & $L$ & $R$ & $L$ & $R$ & $L$ & $R$ & $L$ & $R$ & $L$ & $R$ & $L$ & $R$ & $L$ & $R$ \\
\hline \multirow[t]{2}{*}{$\mathrm{R}$ Torticollis } & 0 & 0 & 1 & 0 & 0 & 2 & 0 & 0 & 0 & 1 & 0 & 0 & 0 & - & - & - & - \\
\hline & 0 & 0 & 1 & 0 & 0 & 1 & 2 & - & - & - & - & - & - & - & - & - & - \\
\hline \multirow{2}{*}{ L Torticollis } & 0 & 0 & 2 & 0 & 0 & 3 & 0 & 1 & 1 & 3 & 0 & 1 & 1 & - & - & - & - \\
\hline & 0 & 0 & 0 & 0 & 0 & 3 & 0 & 0 & 0 & 2 & 0 & 2 & 0 & - & - & - & - \\
\hline \multirow[t]{4}{*}{$\mathrm{R}$ Laterocollis } & 0 & 0 & 3 & 0 & 0 & 0 & 2 & 0 & 0 & 0 & 1 & 0 & 0 & 0 & 2 & 0 & 0 \\
\hline & 0 & 1 & 0 & 0 & 0 & 1 & 1 & 0 & 0 & 0 & 3 & 0 & 0 & - & - & - & - \\
\hline & 0 & 0 & 1 & 0 & 0 & 1 & 3 & 1 & 1 & 1 & 2 & 1 & 1 & - & - & - & - \\
\hline & 0 & 0 & 2 & 0 & 2 & 1 & 2 & 1 & 1 & - & - & - & - & - & - & - & - \\
\hline \multirow[t]{4}{*}{ L Laterocollis } & 0 & 0 & 2 & 0 & 1 & 2 & 0 & 0 & 0 & 3 & 1 & 1 & 0 & - & - & - & - \\
\hline & 0 & 0 & 1 & 0 & 0 & 1 & 0 & 0 & 0 & 3 & 0 & 0 & 0 & 3 & 1 & 0 & 0 \\
\hline & 0 & 0 & 2 & 0 & 0 & 1 & 0 & 1 & 0 & 3 & 0 & 1 & 0 & - & - & - & - \\
\hline & 0 & 0 & 1 & 0 & 0 & 0 & 2 & 1 & 2 & 2 & 0 & 1 & 1 & - & - & - & - \\
\hline \multirow[t]{2}{*}{ Retrocollis } & 0 & 0 & 1 & 0 & 0 & 3 & 0 & 0 & 0 & 2 & 1 & 0 & 0 & 1 & 1 & 0 & 0 \\
\hline & 0 & 0 & 0 & 0 & 0 & 2 & 2 & 0 & 0 & 3 & 1 & 2 & 2 & 3 & 1 & 0 & 0 \\
\hline
\end{tabular}

$\mathrm{R}=$ Right, $\mathrm{L}=$ left; $\mathrm{AO}=$ atlanto-occipital; $\mathrm{AA}=$ atlantoaxial; $\mathrm{LM}=$ lateral masses; $\mathrm{JT}(\mathrm{S})=$ joint $(\mathrm{s})$; $\mathrm{U} / \mathrm{C}=$ uncovertebral

- =not scanned; $0=$ normal; $1=$ minimal degenerative change; $2=$ moderate degenerative change; $3=$ severe degenerative change

Table 3 Side of (moderate or severe) degenerative changes in the cervical spine below C2 in patients with torticollis or laterocollis ( $n=12$; note that 1 patient with left laterocollis had bilateral changes)

\begin{tabular}{lll}
\hline & \multicolumn{2}{l}{$\begin{array}{l}\text { Side of degenerative } \\
\text { changes }\end{array}$} \\
\cline { 2 - 3 } Type of spasmodic torticollis & Right & Left \\
\hline R torticollis or laterocollis & 5 & 1 \\
L torticollis or laterocollis & 1 & 6 \\
\hline
\end{tabular}

$\mathrm{R}=$ Right; $\mathrm{L}=$ left; $\mathrm{p}=0.015$ (Fisher's exact test).

head mobility both ratings were added so that patients could score from $0-12$.

Disability and pain were assessed using the disability and pain subscales of the TWSTRS. Severity of head tremor was scored according to the validated clinical rating scale proposed by Bain et $a l^{34}$ which defines four main categories: no tremor (0), noticeable but mild tremor (1-3), moderate tremor, the tremor may be bothersome to the patient but does not lead to significant functional impairment (4-6), severe tremor present in all head positions (7-9), and extremely severe (10).

STATISTICAL ANALYSIS

For comparison of means of independent samples a $t$ test was carried out. To determine whether an association between primary BT

Table 4 Preoperative characteristics of patients with spasmodic torticollis (ST) with none/minimal versus moderate/severe degenerative changes in the cervical spine

\begin{tabular}{|c|c|c|c|}
\hline & $\begin{array}{l}\text { ST without or only } \\
\text { minimal degenerative } \\
\text { changes }(n=20)\end{array}$ & $\begin{array}{l}S T \text { with moderate or } \\
\text { severe degenerative } \\
\text { changes }(n=14)\end{array}$ & p Value \\
\hline Median age (y (range)) & $53.5(23-61)$ & $53.5(38-66)$ & NS \\
\hline $\operatorname{Sex}(M: F)$ & $10: 10$ & $6: 8$ & NS \\
\hline Mean duration of ST (y (SD)) & $11.5(6.9)$ & $14(8.1)$ & NS \\
\hline Median duration (y (range)) & $10.5(2-26)$ & $12(4-37)$ & \\
\hline \multicolumn{4}{|l|}{ Duration (y) without effective treatment } \\
\hline Mean (SD) & $4.8(4)$ & $10.1(7.2)$ & 0.009 \\
\hline Median (SD) & $3(1-15)$ & $8(1-30)$ & \\
\hline Acute onset after trauma & 1 & 2 & NS \\
\hline Delayed onset after trauma & 3 & 2 & NS \\
\hline Tardive dystonia & 0 & 1 & NS \\
\hline Mean (SD) severity* & $21.2(3.8)$ & $18.8(4.3)$ & NS \\
\hline Mean (SD) disability ${ }^{\star}$ & $14.8(6.4)$ & $15.6(5.8)$ & NS \\
\hline Mean (SD) pain $\star$ & $11.5(5.1)$ & $12.1(2.7)$ & NS \\
\hline Primary BT treatment failure & 3 & 6 & NS \\
\hline Mean (SD) head tilt restriction score & $2.5(2)$ & $4.1(2.2)$ & 0.03 \\
\hline Mean (SD) head turn restriction score & $1.7(2.1)$ & $3.4(2.5)$ & 0.04 \\
\hline \multicolumn{4}{|l|}{ Mean (SD) overall head movement } \\
\hline restriction score & $4.2(3.1)$ & $7.6(4.1)$ & 0.015 \\
\hline Mean (SD) tremor severity & $1.4(1.8)$ & $4.7(2.7)$ & 0.01 \\
\hline
\end{tabular}

^ Determined by the TWSTRS. treatment failure and occurrence of degenerative changes exists and whether the side of degenerative changes is associated with the type of spasmodic torticollis a $\chi^{2}$ test was used (for small sample size Fisher's exact test was used). Changes in severity, disability, and pain before and after surgery were calculated using Wilcoxon matched pairs signed ranks test.

\section{Results}

There were no patients with an anomaly of the craniovertebral junction in our study. Degenerative changes on CT that was carried out in all 34 patients were either absent or minimal (20 patients) or moderate or severe (14 patients, table 2). Cervical spine MRI was performed on the same day as the CT and none showed evidence of a myelopathy.

We grouped patients according to the level and side of degenerative changes seen on CT. From a functional point of view the cervical spine can be divided into a more mobile upper segment (occipital-C1 and C1-C2 joints) and a lower less mobile segment (C2/C3 facet/ uncovertebral joints and below). We grouped degenerative changes in patients accordingly. In all 14 patients with moderate to severe degenerative disease, changes occurred at $\mathrm{C} 2 / \mathrm{C} 3$ and below. Five of these patients also had moderate or severe disease above the C2/C3 level, four of whom had significant changes in the $\mathrm{C} 1$ arch-peg articulation only (one patient with right laterocollis, two with left laterocollis, and one with left torticollis as their main component respectively), and one patient (with right laterocollis) had changes in the $\mathrm{C} 1$ arch-peg and right $\mathrm{C} 1 / \mathrm{C} 2$ lateral mass articulation.

Unilateral degenerative changes at $\mathrm{C} 2 / \mathrm{C} 3$ and below were significantly more likely to occur on the side of the main direction of spasmodic torticollis: patients with left torticollis or laterocollis were more likely to have left sided degenerative changes and vice versa (table 3). The few patients with moderate or severe disease at the $\mathrm{OC} 1 \mathrm{C} 2$ articulations precluded statistical analysis.

We compared the two groups of patients with none or minimal or moderate or severe degenerative changes (table 4). There was no significant difference in age, sex, duration of 
Table 5 Outcome after surgery

\begin{tabular}{|c|c|c|c|c|c|c|}
\hline & \multicolumn{2}{|c|}{$\begin{array}{l}\text { ST without or only minimal } \\
\text { degenerative changes }\end{array}$} & \multirow[b]{2}{*}{$p$ Value } & \multicolumn{2}{|c|}{$\begin{array}{l}\text { ST with moderate or severe } \\
\text { degenerative changes }\end{array}$} & \multirow[b]{2}{*}{$p$ Value } \\
\hline & Before $(n=20)$ & After $(n=14)$ & & Before $(n=14)$ & After $(n=8)$ & \\
\hline Mean (SD) severity* & $21.2(3.8)$ & $15.6(4.8)$ & 0.002 & $18.8(4.3)$ & $17(4.9)$ & 0.46 \\
\hline Mean (SD) disability* & $14.8(6.4)$ & $13.2(8.1)$ & 0.056 & $15.6(5.8)$ & $10.4(7.5)$ & 0.352 \\
\hline Mean (SD) pain ${ }^{\star}$ & $11.5(5.1)$ & $7.3(5.6)$ & 0.004 & $12.1(2.7)$ & $6.4(6)$ & 0.068 \\
\hline Mean (SD) head tilt restriction score & $2.5(2)$ & $1.8(2.2)$ & NS & $4.1(2.2)$ & $4.1(2.2)$ & NS \\
\hline Mean (SD) head turn restriction score & $1.7(2.1)$ & $0.8(1.4)$ & NS & $3.4(2.5)$ & $3.0(2.6)$ & NS \\
\hline $\begin{array}{l}\text { Mean (SD) overall head movement } \\
\text { restriction score }\end{array}$ & $4.2(3.1)$ & $2.9(3)$ & NS & $7.6(4.1)$ & $7.1(4.5)$ & NS \\
\hline Mean (SD) tremor severity & $1.4(1.8)$ & $1.4(2.1)$ & NS & $4.7(2.7)$ & $4.3(2.7)$ & NS \\
\hline
\end{tabular}

^Determined by the TWSTRS.

torticollis, overall severity, degree of disability, or amount of pain (before surgery) as determined by the TWSTRS. However, the duration without adequate treatment differed significantly between the groups. In other words, patients with moderate or severe changes either had a longer interval between onset of symptoms of spasmodic torticollis and start of effective treatment (usually BT injections) or an overall shorter lasting response to BT treatment. Among the moderate or severe change group there was a higher proportion of patients with primary failure of BT treatment (six out of 14) than in the none or minimal degenerative change group ( 3 out of 20 ), but the difference was not significant. However, the proportion of patients with primary BT treatment failure in the moderate or severe group was significantly greater than the expected proportion of primary BT failures in a non-selected group with spasmodic torticollis (less than 10\%) $(p=0.038$, Fisher's exact test). This was not the case in the none or mild change group.

Clinically there were other distinguishing features in the moderate or severe group. Firstly, although there was no difference in overall severity of spasmodic torticollis before surgery between the two groups there was a striking difference in restriction of head movement. Patients in the moderate or severe group were significantly less able to turn or tilt the head to the side contralateral to the dystonic head position than those in the none or mild group (table 4). The combined rating (restriction of contralateral tilt+contralateral turn) was also significantly higher in the first group. Secondly, head tremor was more severe in the moderate or severe group (table 4).

Finally, in the none or mild group $(n=20)$ there was a significant improvement of pain and severity, but not disability, 3 months after surgery. By contrast, in the moderate to severe group ( $n=14)$ none of the three outcome variables changed significantly after surgery (table 5). Head mobility (contralateral turn or tilt) tended to improve after surgery in the none or mild group, but not in the moderate to severe group. Tremor did not change significantly after surgery in either group.

\section{Discussion}

The most striking finding of this study is the occurrence of moderate to severe degenerative changes in the $\mathrm{C} 2 / 3$ facets or below in 14 out of 34 patients with spasmodic torticollis. Osteoarthritis in the cervical spine presents with joint narrowing, obliteration of joint space, subchondral sclerosis, and osteophytosis on plain films, $\mathrm{CT}$, and $\mathrm{MRI}^{36-39}$ and is strongly associated with age. ${ }^{40}$ The degree of degenerative changes encountered is more than would be expected in a patient group with a mean age of 50 years. Premature spondylosis has been documented in generalised dystonia ${ }^{11-26}$ but there is little information on patients with spasmodic torticollis, particularly with regard to primary or secondary failure of BT treatment.

Spondylotic changes in the cervical spine usually occur between $\mathrm{C} 3$ and $C 7^{42}{ }^{43}$ but not above C3. In normal aging the C5/6 uncovertebral joints are most often involved, followed by those at $\mathrm{C} 6 / 7$. Changes in the facet (zygapophyseal) joints usually occur at the $\mathrm{C} 3 / 4, \mathrm{C} 4 / 5$ and $\mathrm{C} 5 / 6$ levels. Overall, the $\mathrm{C} 2 / 3$ level is the least often affected, by contrast with our findings in patients with spasmodic torticollis. The pattern of degenerative changes we found in patients with spasmodic torticollis has previously been described by others ${ }^{11}{ }^{26-28}$ and has also been noted in patients with generalised dystonia. ${ }^{1-1820-22} 2426$

Functional anatomy might help to explain the occurrence of degenerative changes predominantly in the upper cervical segments in patients with spasmodic torticollis. The C2/3 intervertebral joint is a transitional area situated between the upper cervical spine, where there is little flexion or extension and most rotation, and the lower cervical spine, where sagittal plane motion predominates (C5/6 having the greatest range) as well as some rotation. ${ }^{44}$ Nearly $50 \%$ of axial rotation occurs at the $\mathrm{C} 1 / \mathrm{C} 2$ articulations. ${ }^{45}$ There is no or minimal axial rotation at the $\mathrm{OC} 1$ articulations and negligible lateral flexion at the $\mathrm{C} 1 / \mathrm{C} 2$ articulations. ${ }^{46}$ It has been shown that rotation of the $\mathrm{C} 1 / \mathrm{C} 2$ segment does not decrease with age but increases slightly to compensate for the overall decreased motion that occurs in the lower segments. ${ }^{48}$ It is therefore likely that the continuous abnormal and complex head movements that occur in spasmodic torticollis strain the upper cervical spine articulations more than the lower cervical spine, as there is less mobility at lower levels. Moreover, coupling of motion in the spine seems very important in spasmodic torticollis. For example, lateral flexion of the neck to the left will result in rotation of the cervical vertebrae to the left with the spinous process moving to the right. ${ }^{45}$ Hence, if patients with 
spasmodic torticollis have an abnormal posture for prolonged periods, this may result in more complex and asymmetric joint strain than would happen if the head spent more time in the neutral position.

Degenerative changes in the upper cervical spine tended to be unilateral. In patients with moderate to severe degenerative changes, the side of arthritic changes was significantly associated with the direction of spasmodic torticollis (for example, patients with left torticollis or left laterocollis had predominantly left sided degenerative disease and vice versa). Abnormal motion results in increased stress, particularly at joint margins, which is likely to be greater on the side towards which the head is tilted or rotated, accelerating degenerative changes on this side. Levine et $a l^{14}$ studied plain radiographs of the cervical spine of patients with spasmodic torticollis and also found that spondylosis was greater on the side to which the head rotated.

Overall, it seems plausible that head position and sustained non-physiological stress on joints facilitates degenerative disease. ${ }^{50}$ However, degenerative changes were either absent or mild in 20 out of 34 patients in this selected series of patients with spasmodic torticollis. Surprisingly, neither age nor overall duration of spasmodic torticollis differed between the two groups. However, a significant difference was found with respect to duration of inadequate or insufficient treatment and occurrence of degenerative changes. Thus, in the group with moderate or severe changes the interval between onset of symptoms and the start of effective treatment was significantly longer than in the none or minimal group. Similarly, six out of the 14 patients in the moderate or severe group were primary BT injection failures and consequently never had adequate treatment. This proportion of primary BT injection failures was significantly higher than expected in a non-selected group of patients with spasmodic torticollis in which primary failure to BT injections is usually less than $10 \% .^{35}$ Effective treatment with BT may, probably due to improvement of head posture, protect patients from developing premature cervical spondylosis.

Although overall severity on the TWSTR scale did not differ between the two groups, patients in the moderate to severe group had some distinguishing clinical features. Firstly, using a validated rating scale $^{34}$ their head tremor was significantly more severe. Tremulous head movements in spasmodic torticollis are often jerky and complex and could strain cervical joints considerably, particularly in the mobile transition zone of $\mathrm{C} 2 / 3$ between the upper and the lower cervical spine, which may promote the formation of osteophytes. Dystonic head tremor often responds less well to BT treatment $t^{51}$ and this also may put patients with head tremor at higher risk of developing degenerative changes. Secondly, head mobility was significantly more restricted in patients in the moderate to severe group. This finding is probably a consequence of underlying osteoarthritis that in advanced stages will inevitably restrict movement. On the other hand, it might also be argued that a fixed abnormal position may be a risk factor for the development of degenerative cervical spine disease. Sometimes patients develop a relatively fixed head posture shortly after onset of the disease-for example, in acute onset post-traumatic torticollis after minor trauma that usually starts several days and sometimes weeks after the trauma, ${ }^{52}$ in post-traumatic torticollis after cervical spine injury, ${ }^{535}$ or occasionally in tardive dystonia (personal observation). These patients may have an increased risk of developing premature osteoarthritis. Interestingly, three patients with severe degenerative changes had a history of acute onset post-traumatic torticollis, severe cervical spine injury, and tardive dystonia respectively, but only one patient with mild degenerative changes had a history of acute onset after trauma (table 4). However, these numbers are too small to draw firm conclusions.

Three out of 20 and two out of 14 patients in the none or minimal and moderate or severe group respectively gave a history of mild head or neck trauma several months before the onset of dystonic symptoms (table 4), a proportion that is in keeping with reports from the literature. ${ }^{55}$ This has been referred to as delayed onset post-traumatic torticollis, ${ }^{52}$ but clinically these patients are indistinguishable from patients with spasmodic torticollis who do not report a history of trauma. ${ }^{52}$ A history of minor trauma itself does not seem to be a risk factor for developing cervical spondylosis.

Do the degenerative changes we have found in the upper cervical spine matter? Severe myelopathy or radiculopathy caused by degenerative changes in the upper cervical spine can occur in generalised dystonia. ${ }^{11-26}$ However, no patient in our series had myelopathy and clinically there was no detectable weakness in cervical myotomes.

On the other hand compression of the $\mathrm{C} 1 / \mathrm{C} 2$ roots could cause sensory symptoms in the $\mathrm{C} 2$ dermatome. We did not find sensory loss in the $\mathrm{C} 2$ dermatome before surgery in any of our patients but occipital and nuchal pain was a common complaint. Pain is often encountered in spasmodic torticollis and often involves overactive dystonic muscles in the neck. Apart from one patient with severe degenerative changes who reported constant nagging occipital pain starting shortly after a traction manoeuvre which could be interpreted as $\mathrm{C} 2$ radiculopathy, we were unable to recognise a difference in the quality, location, or behaviour of pain in the two groups of patients. Also, their ratings on the TWSTR pain scale were similar before operation. However, our measures may not have been sensitive enough to discern subtle differences in the character of the pain between the groups. The fact that pain significantly improved after peripheral denervation in the none or minimal group but not in the moderate or severe degenerative change group could indicate that pain in the second group is indeed partly caused by osteoarthritis rather than purely by dystonic muscular spasms. However, as the number of patients 
operated on with severe degenerative disease is small, these results must be interpreted with caution. Recently Kutvonen et al, ${ }^{56}$ assessing patients with spasmodic torticollis for the presence, quality, and location of pain using different established pain measurements, found no association with degenerative changes of the cervical spine.

It seems that osteoarthritis compromises treatment outcome as it impairs neck mobility. The proportion of primary BT failures was high in patients with moderate or severe degenerative changes and surgical outcome was unsatisfactory. Three months after surgery, when possible reinnervation that could limit benefit would not be expected to have occurred, patients with no or mild degenerative changes had a significant improvement of severity of torticollis and associated pain. However, in patients with moderate or severe changes none of the outcome variables had improved. Whereas postoperative neck mobility tended to improve in patients with mild osteoarthritis, this was not the case in patients with moderate or severe changes.

In a study of 242 patients with spasmodic torticollis, Jankovic and Schwartz ${ }^{57}$ found that poor treatment response after BT injections was associated with a long duration of disease before starting BT injections, and pointed out that these non-responders often had restricted head mobility. These features match the characteristics of our patients with marked degenerative changes in the cervical spine, which implies that osteoarthritis may limit response to treatment with $\mathrm{BT}$, and also with SPD. Detailed imaging assessment of degenerative changes in the cervical spine may assist in selecting patients likely to benefit from BT and SPD treatment. Although plain radiographs with lower associated radiation dosage, might prove equally useful in separating patients with no or mild disease from those with moderate or severe degenerative disease, CT is necessary to confidently exclude some craniovertebral anomalies and is our investigation of choice in patients with spasmodic torticollis considered for surgery, or with a history of fixed, post-traumatic, or sudden onset torticollis.

\section{Conclusions}

Patients with spasmodic torticollis are at risk of premature degenerative changes in the upper cervical spine that tend to be on the side to which patients turn or tilt their heads. One risk factor for developing degenerative changes was long duration of the disease without adequate treatment. In other words, effective treatment, particularly BT injections, seemed to be protective. Head tremor and severe restriction of head movements were common in patients with moderate or severe degenerative changes and the second factor is likely to be a consequence of degenerative changes. However, both factors may also accelerate the degenerative process. Overall, treatment response after SPD in the group of patients with marked degenerative changes was unsatisfac- tory. These patients do not seem to be good candidates for surgery.

Imaging of the cervical spine should be considered in patients with spasmodic torticollis who present with significantly restricted head mobility and do not adequately respond to treatment. To demonstrate degenerative changes in the spine plain films or CT can be used. Spinal MRI should only be considered when clinical signs of myelopathy are present. As part of our assessment for surgery we now routinely scan patients from the occiput to $\mathrm{C} 4$ using CT.

AM was supported by the Ernst Jung-Stiftung für Wissenschaft und Forschung in Hamburg, Germany and by the Eugen Brehm und Forschun

1 Nutt JG, Muenter MD, Aronson A, et al. Epidemiology of . Mov Disord 1998;3:188-94.

2 Fahn S. Concept and classification of dystonia. Adv Neurol 1988;50:1-8.

3 Fahn S, Bressman SB, Marsden CD. Classification of dystonia. Adv Neurol 1998;78:1-10.

4 Dauer WT, Burke RE, Greene P, et al. Current concepts on the clinical features, aetiology and management of idiopathic cervical dystonia. Brain 1998;121:547-60.

5 Chan J, Brin MF, Fahn S. Idiopathic cervical dystonia: clinical characteristics. Mov Disord 1991;6:119-26.

6 Comella CL, Stebbins GT, Miller S. Specific dystonic factors contributing to work limitations and disability in cervical dystonia. Neurology 1996;46(suppl 2 ):A295.

7 Rondont P, Marachnd MP, Dellatolas G. Spasmodic torticollis: review of 230 patients. Can $\mathcal{F}$ Neurol Sci 1991;18:143-51.

8 Jahanshahi M, Marion MH, Marsden CD. Natural history of adult-onset idiopathic torticollis. Arch Neurol 1990;47: $548-52$.

9 Riski JE, Horner J, Nashold BS. Swallowing function in patients with spasmodic torticollis. Neurology 1990;41: 1443-5.

10 Moreau MS, Cauquil AS, Salon MCM. Static and dynamic balance function in spasmodic torticollis. Mov Disord 1999;14:87-94

11 Waterston JA, Swash M, Watkins ES. Idiopathic dystonia and cervical spondylotic myelopathy. I Neurol Neurosurg Psychiatry 1989;52:1424-6.

12 Hirose G, Kadoya S. Cervical spondylotic radiculomyelopathy in patients with athetoid-dystonic cerebral palsy: clinical evaluation and surgical treatment. $\mathcal{F}$ Neurol Neurosurg Psychiatry 1984;47:775-80.

13 Yamashita Y, Kuroiwa Y. Cervical radiculomyelopathy caused by cerebral palsy (dystonic type): linical evaluation of our 10 cases. Saishin Igaku 1979;34:293-7.

14 Levine RA, Rosenbaum AE, Waltz JM, et al. Cervical spondylosis and dyskinesias. Neurology 1970;20:1194-9.

15 Anderson WW, Wise BL, Itabashi HH, et al. Cervical spondylosis in patients with athetosis. Neurology 1962;12: $410-2$.

16 Tunkel AR, Pasupuleti R, Acosta WR. Improvement of idiopathic torsion dystonia following dystonia-induced cervical subluxation [letter]. I Neurol Neurosurg Psychiatry 1986;49: $957-68$

17 El Mallakh RS, Rao K, Barwick M. Cervical myelopathy secondary to movement disorders: case report. Neurosurgery $1989 ; 24: 902-4$

18 Polk JL, Maragos VA, Nicholas JJ. Cervical spondylotic myeloradiculopathy in dystonia. Arch Phys Med Rehabil 1992;73:389-92.

19 Kidron D, Steiner I, Melamed E. Late-onset progressive radiculomyelopathy in patients with cervical athetoiddystonic cerebral palsy. Eur Neurol 1987;27:164-6.

20 Racette BA, Lauryssen C, Perlmutter JS. Preoperative treatment with botulinum toxin to facilitate cervical fusion in dystonic cerebral pasly. ₹ Neurosurg 1998,88:328-30.

21 Nishihara N, Tanabe G, Nakahara S, et al. Surgical treatment of cervical spondylotic myelopathy complicating treatment of cervical spondylotic myelopathy complicating athetoid

22 Fuji T, Yonenobu K, Fujiwara K, et al. Cervical radiculopathy or myelopathy secondary to athetoid cerebral palsy. $\mathcal{F}$ Bone foint Surg (Am) 1987;69:815-21.

23 Angelini L, Broggi G, Nardocci N, et al. Subacute cervical myelopathy in a child with cerebral palsy. Secondary to torsion dystonia? Childs Brain 1982;9:354-7.

24 Pollak L, Schiffer J, Klein C, et al. Neurosurgical intervention for cervical disk disease in dystonic cerebral palsy. Mov Disord 1998;13:713-7.

25 Reese ME, Msall ME, Owen S, et al. Acquired cervical spine impairment in your adults with cerebral palsy. Dev Med Child Neurol 1991;33:153-66.

26 Adler CH, Zimmerman RS, Lyons MK, et al. Perioperative use of Botulinum toxin for movement disorder-induced cervical spine disease. Mov Disord 1996;11:79-81. 
27 Defazio G, Lepore V, Melpignano C, et al. Cervical radiculopathy following botulinum toxin therapy for cervical dyslopathy following botulinum toxin

28 Traynelis VC, Ryken T, Rodnitzky RL, et al. Botulinum toxin enhancement of postoperative immobilization in patients with cervical dystonia. $\mathcal{F}$ Neurosurg 1992;77:808-9.

29 Bertrand CM. Selective peripheral denervation for spasmodic torticollis: surgical technique, results, and observations in 260 cases. Surg Neurol 1993;40:96-103.

30 Bertrand CM, Molina-Negro P. Selective peripheral denervation in 111 cases of spasmodic torticollis: rationale and results. Adv Neurol 1988;50:638-43.

31 Palmer JD, Bhatia KP, Dressler D, et al. Early results of selective peripheral denervation for cervical dystonia (spasmodic torticollis). Proceedings of the Society of British Neurological Surgeons. Br $\mathcal{F}$ Neurosurgery (in press).

32 Stevens JM, Chong WK, Barber C, et al. A new appraisal of abnormalities of the odontoid process associated with atlanto-axial subluxation and neurological disability. Brain 1994;117:133-48

33 Consky EA, Lang AE. Clinical assessments of patients with cervical dystonia. In: Jancovic J, Hallet M, eds. Therapy with

34 Bain PG, Findley LJ, Atchison P, et al. Assessing tremor severity. F Neurol Neurosurg Psychiatry 1993;56:868-73.

35 Anderson TJ, Rivest J, Stell R, et al. Botulinum toxin treatment of spasmodic torticollis. F R Soc Med 1992;85:524-9.

36 Zapletal J, Hekster REM, Treurniet FEE, et al. MRI of atlanto-odontoid osteoarthritis. Neuroradiology 1997;39: 354-6.

37 Halla spasmodic torticollis, Harin JG. Atlanto-axial (C1C2) facet joint arthritis: distinctive clinical syndrome. Rheumatism 1987;30:577-82.

38 Star MJ, Curd JG, Thorne RP. Atlanto-axial lateral mass osteoarthritis A frequently overlooked ca occipitocervical pain. Spine 1992;17:571-6.

39 Genez BM, Willis JJ, Lowrey CE, et al. CT findings of degenerative arthritis of the atlanto odontoid joint. AfR Am degenerative arthritis of the at

40 Van Saase LCM, Van Romunde LKJ, Cats A, et al. Epidemiology of osteoarthritis: Zoetermeer survey. Comparison of radiological osteoarthritis in a Dutch population
with that in 10 other populations. Ann Rheum Dis 1989;48: with that $271-80$.
41 Zapletal J, de Valois JC. Radiological prevalence of advanced lateral C1-C2 osteoarthritis. Spine 1997;22: advance

42 Lestini WF, Wiesel SW. The pathogenesis of cervical spondylosis. Clin Orthop Relat Res 1989;239:69-93.

43 McCormack BM, Weinstein PR. Cervical spondylosis. An update. West f Med 1996;165:43-51.

44 Mestdagh H. Morphological aspects and biomechanical properties of the vertebroaxial joint (C2-C3). Acta Morphol Neerl Scand 1976;14:19-30.

45 Panjabi MM, White AA. Basic biomechanics of the spine. Neurosurgery 1980;7:76-93.

46 White AA, Panjabi MM. The basic kinematics of the human spine. A review of past and current knowledge. Spine 1978; 3:12-20.

47 Panjabi M, Dvorak J, Duranceau J, et al. Three dimensional movements of the upper cervical spine. Spine 1988;13:72630

48 Dvorak J, Antinnes JA, Panjabi MM, et al. Age and gender related normal motion of the cervical spine. Spine 1992;17: 5393-8.

49 Dvorak J, Penning L, Hayek J, et al. Functional diagnostics of the cervical spine using computer tomography. Neuroradiology 1988;30:132-7.

50 Bohlman HH, Sanford EE. The pathophysiology of cervical spondylosis and myelopathy. Spine 1988;13:843-6.

51 Rivest J, Marsden CD. Trunk and head tremor as isolated manifestations of dystonia. Mov Disord 1990;5:60-5.

52 Tarsy D, Comparison of acute- and delayed-onset posttraumatic cervical dystonia. Mov Disord 1998;13:481-5.

53 Suchowersky O, Calne DB. Non-dystonic causes of torticollis. Adv Neurol 1988;50:501-8.

54 Bridgman SA, McNab W. Traumatic occipital condyle fracture, multiple cranial nerve palsies and torticollis: a case report and review of the literature. Surg Neurol 1992;38: $152-6$.

55 Jankovic J, Leder S, Warner D, et al. Cervical dystonia: clinical findings and associated movement disorders. Neurology 1991;41:1088-91.

56 Kutvonen O, Dastidar P, Nurmikko T. Pain in spasmodic torticollis. Pain 1997;69:279-86.

57 Jankovic J, Schwartz KS. Clinical correlates of response to Botulinum toxin injections. Arch Neurol 1991;48:1253-6. 